\title{
An Evidence-Based Antimicrobial Stewardship Smartphone App for Hospital Outpatients: Survey-based Needs Assessment Among Patients
}

Christianne Micallef ${ }^{1,2}$, BPharm(Hons), MPhil, PhD; Monsey McLeod ${ }^{1,3,4}$, MSc, MPharm, PhD; Enrique Castro-Sánchez ${ }^{1}$, RGN, DipTropNurs, PgDip, MPH, PhD, DLSHTM; Myriam Gharbi ${ }^{1}$, MPH, PhD, PharmD; Esmita Charani $^{1}$, MSc, MPharm; Luke SP Moore ${ }^{1,5}, \mathrm{MBChB}, \mathrm{MRCP}, \mathrm{MSc}, \mathrm{MPH}, \mathrm{DTM} \& \mathrm{H}$, FRCPath; Mark Gilchrist ${ }^{5}$, MPharm, MSc, IPresc, FFRPS, FRPharmS; Fran Husson ${ }^{1}$; Ceire Costelloe ${ }^{1}$, BA(Hons), MSc, PhD; Alison H Holmes ${ }^{1,5}$, MD, MA, MPH, FRCP

\footnotetext{
${ }^{1}$ National Institute for Health Research (NIHR) Health Protection Research Unit in Healthcare Associated Infection and Antimicrobial Resistance, Imperial College, London, United Kingdom

${ }^{2}$ Addenbrooke`s Hospital, Pharmacy Department, Cambridge University Hospitals National Health Service (NHS) Foundation Trust, Cambridge, United Kingdom

${ }^{3}$ School of Pharmacy, Centre for Medication Safety and Service Quality, University College London, London, United Kingdom

${ }^{4}$ Imperial College Healthcare National Health Service (NHS) Trust, Pharmacy Department, London, United Kingdom

${ }^{5}$ Imperial College Healthcare National Health Service (NHS) Trust, Infectious Diseases Department, London, United Kingdom
}

\section{Corresponding Author:}

Christianne Micallef, BPharm(Hons), MPhil, PhD

National Institute for Health Research (NIHR) Health Protection Research Unit in Healthcare Associated Infection and Antimicrobial

Resistance

Imperial College

Hammersmith Campus

London W12 0NN

United Kingdom

Phone: 4402033132732

Fax: 4402033130592

Email: c.micallef@imperial.ac.uk

\section{Abstract}

Background: Current advances in modern technology have enabled the development and utilization of electronic medical software apps for both mobile and desktop computing devices. A range of apps on a large variety of clinical conditions for patients and the public are available, but very few target antimicrobials or infections.

Objective: We sought to explore the use of different antimicrobial information resources with a focus on electronic platforms, including apps for portable devices, by outpatients at two large, geographically distinct National Health Service (NHS) teaching hospital trusts in England. We wanted to determine whether there is demand for an evidence-based app for patients, to garner their perceptions around infections/antimicrobial prescribing, and to describe patients' experiences of their interactions with health care professionals in relation to this topic.

Methods: A cross-sectional survey design was used to investigate aspects of antimicrobial prescribing and electronic devices experienced by patients at four hospitals in London and a teaching hospital in the East of England.

Results: A total of 99 surveys were completed and analyzed. A total of $82 \%(80 / 98)$ of respondents had recently been prescribed antimicrobials; $87 \%$ (85/98) of respondents were prescribed an antimicrobial by a hospital doctor or through their general practitioner (GP) in primary care. Respondents wanted information on the etiology $(42 / 65,65 \%)$ and prevention and/or management $(32 / 65,49 \%)$ of their infections, with the infections reported being upper and lower respiratory tract, urinary tract, oral, and skin and soft tissue infections. All patients $(92 / 92,100 \%)$ desired specific information on the antimicrobial prescribed. Approximately half (52/95, 55\%) stated it was "fine" for doctors to use a mobile phone/tablet computer during the consultation while 13\% (12/95) did not support the idea of doctors accessing health care information in this way. Although only $30 \%$ (27/89) of respondents reported on the use of health care apps, 95\% (81/85) offered information regarding aspects of antimicrobials or infections that 
could be provided through a tailored app for patients. Analysis of the comments revealed the following main global themes: knowledge, technology, and patient experience.

Conclusions: The majority of respondents in our study wanted to have specific etiological and/or infection management advice. All required antimicrobial-related information. Also, most supported the use of electronic resources of information, including apps, by their doctors. While a minority of people currently use health apps, many feel that apps could be used to provide additional support/information related to infections and appropriate use of antimicrobials. In addition, we found that there is a need for health care professionals to engage with patients and help address common misconceptions around the generation of antimicrobial resistance.

(JMIR Mhealth Uhealth 2016;4(3):e83) doi: $10.2196 /$ mhealth.5243

\section{KEYWORDS}

mobile electronic devices; mHealth; mobile health; antimicrobial resistance; patient involvement

\section{Introduction}

The increasing burden of antimicrobial resistance is a well-known global phenomenon which requires national [1] and international collaboration [2] for effective prevention, control, and management. Indeed, it is estimated that antimicrobial resistance (AMR) currently claims 50,000 lives per year across Europe and the United States [3]. The current forecast suggests that if the situation remains unchecked, AMR will be the leading cause of death in humans by 2050, surpassing cancer and diabetes-related diseases, claiming 10 million deaths annually and leading to economic losses of US \$100.2 trillion [3].

Medical health technology apps offer a practical way to increase accessibility and navigability of medical information during routine provision of patient care by health care professionals. The benefits of medical apps to facilitate optimal patient care and self-management has recently been reported in sexual health [4], HIV/AIDS management [5], increasing fitness levels [6], and cancer prevention [7] in rural communities.

A number of studies have also explored and evaluated the use of apps targeted at people living with a range of clinical conditions, including diabetes [8], asthma [9], and stroke [10]. Apps have also been used to aid in self-care in women`s health [11] and mental health [12,13], and to support patients undergoing bariatric [14] and colorectal surgery [15]. These and other studies [16] delineate a consistent lack of governance around medical apps, thereby presenting significant implications for patient safety. Furthermore, many lack appropriate health care professional input and it is unclear how the needs of the target users were incorporated into the functionality and content of such apps.

A range of infection prevention and control and antimicrobial-related apps are available for medical and other clinical staff [17-20], however, to our knowledge there is as yet no study exploring the usability of apps for patients specifically targeting infections and/or antimicrobial use. In addition, a UK Wellcome Trust report [21] has provided important insights into the perception of antimicrobial resistance by the general public in the United Kingdom; the report concluded that there is a problem with communicating issues around antimicrobial resistance and an urgent need to educate the public in this field. Moreover, a recent systematic review [22] on the public's knowledge and beliefs about antibiotic resistance confirmed the lack of understanding about the development of AMR and misperceptions about its causes. Providing patients and the public with appropriate information around infections and antimicrobial therapy using electronic resources, such as mobile phones, tablets, and personal computers, may help address this need.

We sought to explore the use of different antimicrobial therapy information resources with a focus on electronic platforms, including apps for portable devices by health care users at two large, geographically distinct teaching hospitals in England. We wanted to determine whether there is currently a need for an evidence-based app for patients, to garner public perceptions around infections/antimicrobial prescribing, and to describe patients' experiences of their interactions with health care professionals in relation to this topic.

\section{Methods}

\section{Overview}

A cross-sectional study was designed using a 12-item survey investigating aspects of antimicrobial prescribing and electronic devices experienced by patients or their carers. The following participants were involved in the design of the questions and survey format: an infectious diseases physician; three hospital pharmacists, all with infection expertise; an academic lead nurse; a public health specialist; and a patient representative. A single open question invited respondents to annotate any comments they wished to make about the survey itself and/or any aspect on antimicrobial prescribing, resistance, and infections. Feedback from a patient hospital coordinator was used to check the survey compliance with National Health Service (NHS) readability requirements for materials provided to patients and the general public [23].The survey was then piloted with potential respondents for face validity.

\section{Data Exclusion}

Inclusion criteria for participation included being $\geq 18$ years of age and participants or their dependants having taken a course of antimicrobials in the previous 6 months. Any respondents who did not meet the above criteria were automatically excluded. Although requested, this study did not require ethics committee approval, as confirmed by the NHS Research Ethics 
Committee, as this work was considered to be a service evaluation.

\section{Recruitment}

The survey was distributed by pharmacy outpatient staff to people attending four different hospitals across two acute NHS institutions, from September 15-30, 2014, in London and from November 18, 2014, to February 23, 2015, in Cambridge, until a convenience sample of 100 consecutive respondents had been reached. A master copy of the survey is provided in Multimedia Appendix 1. A raffle incentive- $£ 30$ shopping vouchers, one for each geographical location-was offered to respondents who completed the survey.

\section{Data Analysis}

Data were anonymized and reported using descriptive statistics. Additionally, analysis of the free-text comments portion of the survey and the feedback provided by the respondents was conducted [24]. This was done by a single researcher (CM) who grouped the comments received into main and global themes. The themes were then reviewed and corroborated by the study team.

\section{Results}

\section{Demographics and Ownership of Electronic Devices}

A total of 100 surveys were returned, but only 99 (99.0\%) surveys were eligible to be included in the analysis - one survey was excluded as the respondent was under 18 years of age. Not all respondents completed each question in the survey and this was taken into account in the analysis. For each question the number of respondents is given.

The median age of respondents $(n=85)$ was 40 years (range 19-99), and $8 \%$ were over 70 years of age. Table 1 provides details on respondent demographics.

Table 1. Demographics of the patient sample .

\begin{tabular}{ll}
\hline Patient characteristics & $\mathrm{n}(\%)$ \\
\hline $\begin{array}{l}\text { Gender (female) }(\mathbf{n}=\mathbf{9 6}) \\
\text { Level of education }(\mathbf{n}=\mathbf{8 8})\end{array}$ & $46(48)$ \\
Degree & $46(52)$ \\
Other qualifications & $29(33)$ \\
No qualifications & $13(15)$ \\
Personal electronic device owned (n=89) & \\
Desktop/laptop & $62(70)$ \\
Android mobile phone & $36(40)$ \\
Android tablet & $15(17)$ \\
Apple mobile phone & $40(45)$ \\
Apple tablet & $27(30)$ \\
Windows-based mobile phone & $6(7)$ \\
Windows-based tablet & $3(3)$ \\
Blackberry mobile phone & $1(1)$ \\
Other device & $4(4)$ \\
No device & $8(9)$ \\
\hline
\end{tabular}

\section{Antimicrobial Prescribing and Obtaining Information on Antimicrobials/Infections}

In all, 82\% (80/98) of respondents had recently been prescribed antimicrobials for themselves and 19\% (19/98) stated that their dependants/children were prescribed antimicrobials. A total of $87 \%(85 / 98)$ of respondents were prescribed an antimicrobial by a doctor, either in hospital or in the community. The remaining 13 individuals out of 98 (13\%) stated that they acquired their prescription from the one of the following: dentist $(4 / 98,4 \%)$, nurse $(5 / 98,5 \%)$, hospital pharmacist $(1 / 98,1 \%)$, walk-in clinic while on holiday $(1 / 98,1 \%)$, and by self-prescription $(2 / 98,2 \%)$. When asked how they obtained information about the antimicrobials prescribed or the infection treated, $80 \%(74 / 93)$ said they had asked a health care professional (HCP) such as a doctor, pharmacist, or nurse. A total of $7 \%(6 / 93)$ had asked family and friends and $17 \%(16 / 93)$ had also searched the Internet. However, only $60 \%$ (51/85) of respondents were completely satisfied with the information they had been given by their HCPs.

In terms of the information that respondents wanted to know about their particular infection, 65\% (42/65) wanted information on the etiology of the infection. Most common infections mentioned were as follows: upper and lower respiratory tract infections; urinary tract infections; and oral, skin, and soft tissue infections. In addition, $49 \%$ (32/65) wanted information on the prevention and/or management of their infection. When asked whether they wanted any specific information relating to the antibiotics prescribed, all the respondents who answered this question $(92 / 92,100 \%)$ desired at least one particular piece of information among the following: best time of day to take 
antibiotics, whether the antibiotics should be taken with food, whether alcohol could be consumed, whether the antibiotics could be taken at the same time as other medicines, what to do about a missed dose, and side effects. Some patients also added their own comments, for example, the patient information leaflet used, the ability of antibiotics to induce thrush, age group of people who could take the antibiotic, safety in pregnancy, and safety in blood disorders (eg, thalassemia).
Table 1 also provides information on the electronic devices owned by patients. While $30 \%$ (27/89) of patients used health care apps, 95\% (81/85) completed a preference list of statements on aspects of antimicrobials and/or infections that could potentially be provided through a dedicated app for patients (see Table 2).

Table 2. Preferences for an antimicrobial app and patients' perceptions on the utilization of electronic platforms by health care professionals.

\begin{tabular}{|c|c|c|}
\hline Parameter & & $\mathrm{n}(\%)$ \\
\hline \multicolumn{3}{|c|}{ Characteristics of a dedicated antimicrobial app for patients/public $(\mathrm{n}=\mathbf{8 5})$} \\
\hline & Treatment of symptoms & $64(75)$ \\
\hline & Side-effects of antimicrobials & $60(71)$ \\
\hline & Duration of common infections & $53(62)$ \\
\hline & Tips on how to reduce risk of getting common infections & $49(58)$ \\
\hline & Are antimicrobials indicated for my infection? & $48(56)$ \\
\hline & When do I need to see my doctor? & $47(55)$ \\
\hline & Signs of bacterial versus viral chest infections & $43(51)$ \\
\hline & Recording of antimicrobial treatment information & $30(35)$ \\
\hline & Other information (free text) & $5(6)$ \\
\hline \multicolumn{3}{|c|}{ Patients' perceptions on use of mobile electronic devices during a consultation with a doctor $(n=95)$} \\
\hline & Fine to use & $52(55)$ \\
\hline & Not fine, they should not be using it & $12(13)$ \\
\hline & Depends on the situation & $22(23)$ \\
\hline & Other: specific scenario given & $9(9)$ \\
\hline
\end{tabular}

\section{Analysis of Respondents' Feedback}

Additional insights on their experience with antimicrobials, infections, and apps were provided by $15 \%$ (15/99) of respondents, and are presented in detail in Table 3.
The main themes were patient information leaflets, information on infections/antimicrobials, technology awareness, and personal experience on infections/antimicrobial prescribing. 
Table 3. Themes emerging from respondents' feedback ${ }^{\mathrm{a}}$.

\begin{tabular}{|c|c|c|c|}
\hline Global theme & Main theme & Verbatim comment & Respondent character \\
\hline \multicolumn{4}{|l|}{ Knowledge } \\
\hline & \multicolumn{3}{|l|}{ Patient information leaflets } \\
\hline & & $\begin{array}{l}\text { "Leaflets included with medicines are a pain. Too clumsy and } \\
\text { contain information overload." }\end{array}$ & Male, no age supplied \\
\hline & & $\begin{array}{l}\text { "Leaflet is fine for most people to read but needs to be concise } \\
\text { and to the point, for example, if you miss a tablet don't take it. } \\
\text { Tips: major things in BOLD writing." }\end{array}$ & Female, 60 years old \\
\hline & $\begin{array}{l}\text { Information on infections } \\
\text { and/or antimicrobials }\end{array}$ & & \\
\hline & & $\begin{array}{l}\text { "Would be useful to know why certain antibiotics are prescribed } \\
\text { over others. In my case was prescribed antibiotics that didn`t } \\
\text { work." }\end{array}$ & Female, 27 years old \\
\hline & & "Length of time till symptoms don`t ease-implications of this." & Male, 29 years old \\
\hline & & $\begin{array}{l}\text { "Information needed on gaps one should leave between antibiotic } \\
\text { courses, in order to reduce problems with resistance." }\end{array}$ & Male, 60 years old \\
\hline & & $\begin{array}{l}\text { "Gap one should leave between antibiotic courses in order to de- } \\
\text { crease resistance." }\end{array}$ & Male, 66 years old \\
\hline & & $\begin{array}{l}\text { "This survey is very interesting. It is making you actually think } \\
\text { about the issues around taking medications." }\end{array}$ & Female, 48 years old \\
\hline & & "Information is good but does not beat real medical assessment." & Male, 39 years old \\
\hline \multicolumn{4}{|l|}{ Technology } \\
\hline & \multicolumn{3}{|l|}{ Technology awareness } \\
\hline & & $\begin{array}{l}\text { "Prefer than app, comprehensive website optimized for phones } \\
\text { and tablets." }\end{array}$ & Male, 33 years old \\
\hline & & "This survey could be an APP!" & Female, 43 years old \\
\hline & & "Doctors need to keep up to date with technology." & Male, 40 years old \\
\hline
\end{tabular}

Patient experience

Personal experience with infections/antimicrobial prescribing

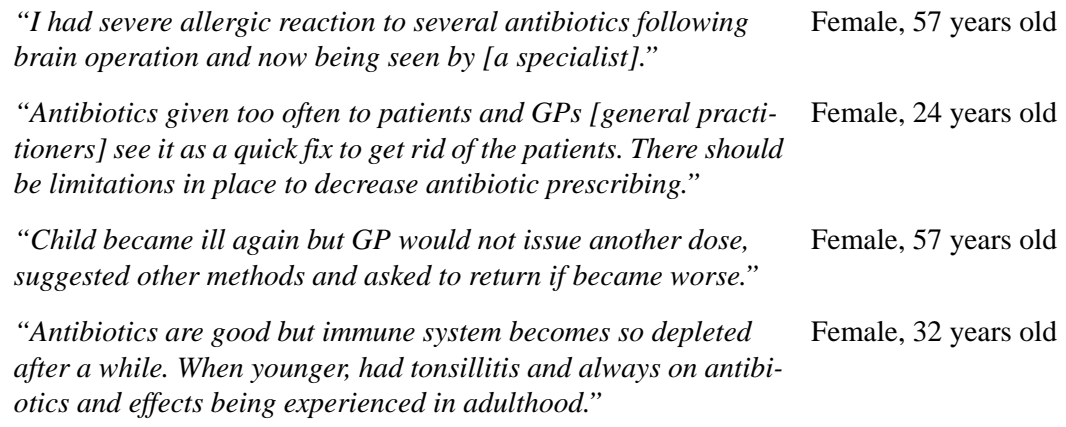

a'Only superfluous comments were excluded (eg, "great" or "I have a carer"); the rest are all included in the table.

\section{Discussion}

\section{Principal Findings}

In this study, we present findings indicating that the majority of patients are prescribed antimicrobials by a doctor. Two-thirds of the patients wanted information on the etiology of the infection and half of them requested information on optimal management of the infection. All wanted antimicrobial-specific information. Also, about half of the respondents supported doctors using electronic platforms to access medical information during a consultation. In addition, ownership of electronic devices was relatively high within our sample population of people attending NHS outpatient pharmacies. Three-quarters of those who were recently prescribed an antimicrobial stated that they owned a computer and nearly half of respondents owned an Android or Apple mobile phone. Although only 30\% of respondents used apps, 95\% suggested useful features to include in a bespoke app targeting antimicrobials/infections. 
We also identified that a significant number of those attending outpatient clinics in a hospital setting, which might also include members of the general public or even NHS staff, besides patients, were not always satisfied with the quality of information received. Overall, our findings suggest that there is a gap and demand by some patients and possibly members of the public for an app that provides antimicrobial- and infection-specific information. Collectively, the global themes that emerged from the respondents' feedback were knowledge, technology, and patient experience.

\section{Patient Information Leaflets}

Patient information leaflets failed to provide patients with easily understandable and useful information (eg, "Leaflets included with medicines are a pain," "Too clumsy and contain information overload"). Some respondents suggested that a dedicated app with practical information might address this gap.

A recent Patient Safety Alert [25] has emphasized the need for health care institutions to engage with patients in order to optimize the use of antimicrobial agents and help prevent the spread of resistant microorganisms. This alert also references the National Institute for Health and Care Excellence (NICE) guidance on antimicrobial stewardship [26], which focuses on patient-centered care and involving patients in their treatment plans, also noting their perceptions about antimicrobial prescribing, whether or not an antimicrobial is indicated.

\section{Information on Infections/Antimicrobials}

Some respondents had scientifically incorrect views and opinions about the misuse of antimicrobials, which clearly indicates the need for targeted, patient-centered antimicrobial stewardship educational interventions. For instance, one patient stated, "Information needed on gaps one should leave between antibiotic courses, in order to reduce problems with resistance." Another patient stated, "Antibiotics are good, but immune system becomes so depleted after a while. When younger, had tonsillitis and always on antibiotics and effects being experienced in adulthood." Echoing the findings highlighted in the Wellcome report [21], our respondents constructed an understanding of antimicrobial resistance around the idea of their bodies "getting used to" antibiotics rather than as an adaptive response from microorganisms. As mentioned in the report [21], there is an urgency to address these misconceptions from a public health perspective.

\section{Technology Awareness}

While some respondents strongly supported technological innovations in health care-for instance, one respondent stated, "Doctors need to keep up to date with technology" - there may be concerns about privacy and medical data protection, as a small proportion of people in our study (13\%) were not happy with doctors accessing electronic resources using a mobile phone/tablet during a consult. These feelings may be explained by wider societal concerns about the misuse of confidential information and data breaches, as well as perceptions of the robustness of security mechanisms and tools.

\section{Personal Experience on Infections/Antimicrobial Prescribing}

Some individuals felt strongly about their own personal/family experiences with infections, which highlights the individual angst and emotive issues experienced by people affected by an infectious disease. Examples include the following: "Antibiotics given too often to patients and GPs [general practitioners] see it as a quick fix to get rid of the patients. There should be limitations in place to decrease antibiotic prescribing" and "I had severe allergic reaction to several antibiotics following brain operation and now being seen by [a specialist]." This could also possibly be linked to the suboptimal level of satisfaction experienced by some of our respondents when they asked their HCPs about their infections/antimicrobials.

\section{Limitations}

Since only 100 respondents completed the survey and we analyzed 99 (99.0\%), our results cannot be widely generalized. However, people from multiple NHS sites participated, which included two distinct geographical locations.

Some individuals also chose not to reply to certain questions and this potentially might have affected our final analysis, but we could only analyze the responses that we obtained. We used closed-ended questions which limited the responses, but we tried to balance this by including an Other, please specify category for respondents to provide any additional comments, in addition to an open-ended question. Since part of the recruitment coincided with European Antibiotic Awareness Day (EAAD), it cannot be ignored that this public health awareness campaign, and possibly other related media coverage, might have influenced respondents' feedback.

\section{Comparison With Prior Work}

A US study surveyed adult patients attending an emergency department (ED) [27] and found that from 300 respondents, a total of $71 \%$ owned a smartphone-from these, $33 \%$ were males-with $95 \%$ overall stating that they had apps and $44 \%$ stating that they had health-related apps. The median age was 29 years. In our study, only $30 \%$ of respondents stated that they had health-related apps and the median age of our respondents was 40 years, so it is possible that age may play a role in determining whether patients regularly access health-related apps. Also, since the patients in the US ED study were younger than the ones in this study, and specifically attended the ED, their disease conditions may have been acute, while in our study the respondents may have had more chronic conditions. Another study [28] targeted patients attending an outpatient psychiatric clinic in Boston, MA, USA. A total of 100 patients were given an uncompensated survey (ie, not offered any incentive e.g. payment, vouchers, etc) to complete and $72 \%$ stated that they owned a smartphone. Overall, more than 50\% indicated that they would use an app daily for monitoring their mental health condition if this was made available. In this study, patients in the 30-45-year-old age range were more likely to show interest in downloading a mobile phone app to monitor their mental health conditions.

With the increasing availability of health care apps for medical and allied health care professionals, and also as highlighted in 
a systematic review on health care apps for mobile phones [29], we were interested in exploring patients' opinions on the use of mobile phones/tablets by medical professionals during a consult. Over half of the respondents stated that they were happy for the doctors to use them, but $13 \%$ categorically declared that they were not happy; the majority of these respondents were female, but the numbers were small. Nearly one-third of the respondents selected depends on the situation, some adding that if the resource was NHS-approved or if their particular clinical condition was exceptional, they would not object. This finding may indicate a lack of trust in the use of highly sensitive confidential information, with the fear that this might be shared with third parties and/or an expectation that their doctor should know it all.

We also wanted to find out what personal electronic devices were being used by respondents, as this information would enable us to assess how patients obtained information and what electronic devices they used. The majority $(62 / 89,70 \%)$ used a desktop or laptop computer. Almost half of the respondents used an Android or Apple mobile phone. Tablet usage was less, with 17\% (15/89) using an Android tablet versus 30\% (27/89) using an Apple tablet. Interestingly, very few had Windows-based devices; only $1 \%(1 / 89)$ had a Blackberry mobile phone, but $9 \%$ (8/89) stated that they did not use any electronic devices. Market research data shows that mobile device usage has overtaken desktop computer usage since 2014; in the United States, mobile digital media time is higher at $51 \%$ for mobile devices versus $42 \%$ for desktop or laptop computers [30]. UK data [31] demonstrates that the number of adults who own a mobile phone has risen from 61\% (Quarter 1, 2014) to $66 \%$ (Quarter 1, 2015); the number of people using their mobile handsets to access the Internet has also increased, from $57 \%$ (Quarter 1, 2014) to 61\% (Quarter 1, 2015). In addition, 4G mobile subscriptions have dramatically increased from 2.7 million (end of 2013) to 23.6 million (end of 2014).

We explored processes around infection and antimicrobial prescriptions and can report that the majority of patients in our study were prescribed antimicrobials for personal use by a medical practitioner. More than half of our respondents obtained information regarding their infection or antimicrobials directly from their doctor, nurse, or pharmacist. However, when asked about their level of satisfaction, it was interesting to note that only $60 \%$ felt completely satisfied by the information they received. This finding may pose the question, "Do patients really understand the information being given to them by health care professionals?" as this could lead to suboptimal medication compliance. A Japanese study [32] addressed the issue of medication adherence by developing a smartphone medication self-management system based on interviews with 116 patients with chronic illnesses. Separately, a meta-analysis investigating 13 randomized controlled trials (RCTs) [33] found that electronic medication counseling improved adherence with antiretroviral therapy, as well as virologic response, when compared to control groups not receiving the counseling. However, this was only significant when it was one of multiple components in the intervention, not when it was the sole intervention. Our study does not highlight why patients were not satisfied, so there could be many other reasons, possibly related to HCPs not providing sufficient information, HCPs providing an inappropriate format for the intended patient, and a lack of time to establish understanding/address patients' questions and concerns.

The three most common features that patients desired in an app included the following: treatment of their symptoms (75\%), side-effect profile $(71 \%)$, and duration of common infections $(62 \%)$. This finding is very useful and could inform the design of a bespoke app targeted at facilitating the appropriate use of antibiotics by patients. It also identifies a potential gap in current public awareness campaigns around infections/antimicrobials, which needs to be addressed. From our results, it could be inferred that patients, and possibly some members of the general public, would like to have targeted information on self-care and management of infections that includes duration of these infections, as well as important considerations relating to antimicrobials.

The IMS Health report [34] issued by the IMS Institute for Healthcare Informatics, USA, identified 165,000 mHealth apps currently available to the general public, with $>90 \%$ of these being free of charge. Some of these apps may well be infection/antimicrobial related, however, the report states that most have limited functionalities. Separately, a European Union (June 2015) project on eHealth and well-being [35] published a comprehensive list of eHealth apps receiving funding that failed to include any projects on antimicrobials or infections, indicating a significant missed opportunity.

In addition, both the Wellcome Trust report (2015) [21] and a systematic review [22] on the public's knowledge and beliefs on AMR suggest that more needs to be done to understand how people perceive the problem of antimicrobial resistance. Also, a careful assessment of the processes and methodologies that are needed to employ and better equip both patients and the public needs to be conducted, so they may grasp the basic concepts of this phenomenon and help curb antimicrobial resistance. Although our survey was conducted in hospital outpatient pharmacies where it is expected that most of the customers would be chronic patients receiving hospital treatment, the pharmacies are easily accessed by visitors and even NHS staff, so these too could have contributed to the survey responses - this data was unavailable as we did not capture it; as well, responses were anonymized. Hence, we postulate that the responses given in our survey could also very likely include members of the public.

\section{Conclusions}

Our findings suggest that the patients and possibly the general public would like easily accessible information about the etiology and management of infections. All of our respondents wanted information relating to the antimicrobials prescribed. We found that ownership of mobile electronic devices was high among respondents to our survey and patients are aware of the availability of health care information using modern electronic resources. We found that a significant proportion of respondents also supported the use of electronic platforms by health care professionals to access medical information. 
Furthermore, our results show that there is a potential for developing an evidence-based app for patients and possibly the general public targeting infections and antimicrobials. This app would also help support HCPs to provide the necessary information on antimicrobials/infections, as required by national UK guidance.

However, prior to designing and developing an app, further work should be conducted, ideally by designing a new survey seeking more in-depth information about how the creation of a bespoke app would be used by patients. In addition, focus group interviews with patients and the public should be employed to address some of the misconceptions identified in our study around the generation of antimicrobial resistance, as well as the global themes concerning knowledge, technology, and patient experience around infections and antimicrobial therapy.

\title{
Acknowledgments
}

This research was partially funded by the National Institute for Health Research (NIHR) Health Protection Research Unit (HPRU) in Healthcare Associated Infection and Antimicrobial Resistance at Imperial College London, in partnership with Public Health England (PHE), the NIHR Imperial Biomedical Research Centre, and the NIHR Imperial Patient Safety Translational Research Centre. The views expressed are those of the authors and not necessarily those of the NHS, the NIHR, the Department of Health, or Public Health England. This work was supported by Imperial College Healthcare Charity (grant no. 7006/P36U).

The authors would like to thank Professor Cliodna McNulty, Head of Primary Care Unit, Public Health England, for her support and contribution to the early phases of the research, including the design of the survey. We are grateful to the outpatient pharmacy NHS and Lloyds staff; Mrs Aleksandra Scibor-Stiepen, Specialist Antimicrobials Pharmacy Technician, Addenbrooke`s Hospital; patients, visitors, and NHS staff at Imperial College Healthcare NHS Trust; and Addenbrooke`s Hospital, Cambridge University Hospitals, NHS Foundation Trust, who helped distribute the surveys and/or participated.

\section{Conflicts of Interest}

CM has received travel grants to attend scientific conferences from Astellas, Gilead, Pfizer and Novartis and educational grants from Pfizer and Novartis. CM has attended a Pfizer Advisory Board Meeting and consulted for Astellas. ECS has received funding from the Florence Nightingale Foundation to study the participation of nurses in antimicrobial stewardship decisions. MG (Mark Gilchrist) reports attending advisory boards for The Medicines Company, Clinigen, Astellas Pharmaceuticals, and Cubist/ Merck, and receiving educational travel and speaker grants from Eumedica Pharmaceuticals and Astellas Pharmaceuticals, Sanofi, respectively. AHH and LSPM have consulted for bioMérieux.

Part of this work was presented as a poster at the 25th European Congress for Clinical Microbiology and Infectious Diseases (ECCMID) held in Copenhagen, Denmark, April 25-28, 2015.

\section{Multimedia Appendix 1}

\author{
[PDF File (Adobe PDF File), 87KB-Multimedia Appendix 1]
}

\section{References}

1. Department of Health. Annual Report of the Chief Medical Officer. Volume Two. London, UK: Department of Health; 2011. URL: https://www.gov.uk/government/uploads/system/uploads/attachment data/file/138331/ CMO Annual Report Volume 2 2011.pdf [accessed 2016-06-27] [WebCite Cache ID 6iaFWGpNR]

2. World Health Organization. The Evolving Threat of Antimicrobial Resistance: Options for Action. Geneva, Switzerland: World Health Organization; 2012. URL: http://apps.who.int/iris/bitstream/10665/44812/1/9789241503181 eng.pdf [accessed 2016-06-27] [WebCite Cache ID 6iaFwVyzV]

3. Antimicrobial Resistance: Tackling a Crisis for the Health and Wealth of Nations. 2014 Dec. URL: http://amr-review.org/ $\underline{\text { sites/default/files/ }}$

AMR\%20Review\%20Paper\%20-\%20Tackling\%20a\%20crisis\%20for\%20the\%20health\%20and\%20wealth\%20of\%20nations 1. pdf [accessed 2016-06-20] [WebCite Cache ID 6iPFA896K]

4. Kirby T, Thornber-Dunwell M. Phone apps could help promote sexual health in MSM. Lancet 2014 Oct 18;384(9952):1415. [doi: 10.1016/S0140-6736(14)61849-3] [Medline: 25390311]

5. Perera AI, Thomas MG, Moore JO, Faasse K, Petrie KJ. Effect of a smartphone application incorporating personalized health-related imagery on adherence to antiretroviral therapy: A randomized clinical trial. AIDS Patient Care STDS 2014 Nov;28(11):579-586 [FREE Full text] [doi: 10.1089/apc.2014.0156] [Medline: 25290556]

6. Casey M, Hayes PS, Glynn F, OLaighin G, Heaney D, Murphy AW, et al. Patients' experiences of using a smartphone application to increase physical activity: The SMART MOVE qualitative study in primary care. Br J Gen Pract 2014 Aug;64(625):e500-e508 [FREE Full text] [doi: 10.3399/bjgp14X680989] [Medline: 25071063]

7. Ginsburg OM, Chowdhury M, Wu W, Chowdhury MT, Pal BC, Hasan R, et al. An mHealth model to increase clinic attendance for breast symptoms in rural Bangladesh: Can bridging the digital divide help close the cancer divide? Oncologist 2014 Feb;19(2):177-185 [FREE Full text] [doi: 10.1634/theoncologist.2013-0314] [Medline: 24396050] 
8. Huckvale K, Adomaviciute S, Prieto JT, Leow MK, Car J. Smartphone apps for calculating insulin dose: A systematic assessment. BMC Med 2015;13:106 [FREE Full text] [doi: 10.1186/s12916-015-0314-7] [Medline: 25943590]

9. Huckvale K, Morrison C, Ouyang J, Ghaghda A, Car J. The evolution of mobile apps for asthma: An updated systematic assessment of content and tools. BMC Med 2015;13:58 [FREE Full text] [doi: 10.1186/s12916-015-0303-x] [Medline: 25857569]

10. Dubey D, Amritphale A, Sawhney A, Amritphale N, Dubey P, Pandey A. Smart phone applications as a source of information on stroke. J Stroke 2014 May;16(2):86-90 [FREE Full text] [doi: 10.5853/jos.2014.16.2.86] [Medline: 24949314]

11. Derbyshire E, Dancey D. Smartphone medical applications for women's health: What is the evidence-base and feedback? Int J Telemed Appl 2013;2013:782074 [FREE Full text] [doi: 10.1155/2013/782074] [Medline: 24454354]

12. Harrison AM, Goozee R. Psych-related iPhone apps. J Ment Health 2014 Feb;23(1):48-50. [doi: 10.3109/09638237.2013.869575] [Medline: 24484194]

13. Shen N, Levitan M, Johnson A, Bender JL, Hamilton-Page M, Jadad AA, et al. Finding a depression app: A review and content analysis of the depression app marketplace. JMIR Mhealth Uhealth 2015;3(1):e16 [FREE Full text] [doi: 10.2196/mhealth.3713] [Medline: 25689790]

14. Stevens DJ, Jackson JA, Howes N, Morgan J. Obesity surgery smartphone apps: A review. Obes Surg 2014 Jan;24(1):32-36. [doi: 10.1007/s11695-013-1010-3] [Medline: 23749609]

15. O'Neill S, Brady RR. Colorectal smartphone apps: Opportunities and risks. Colorectal Dis 2012 Sep;14(9):e530-e534. [doi: 10.1111/j.1463-1318.2012.03088.x] [Medline: 22646729]

16. Charani E, Castro-Sánchez E, Moore LS, Holmes A. Do smartphone applications in healthcare require a governance and legal framework? It depends on the application!. BMC Med 2014;12:29 [FREE Full text] [doi: 10.1186/1741-7015-12-29] [Medline: 24524344]

17. Burdette SD, Trotman R, Cmar J. Mobile infectious disease references: From the bedside to the beach. Clin Infect Dis 2012 Jul;55(1):114-125 [FREE Full text] [doi: 10.1093/cid/cis261] [Medline: 22679027]

18. Charani E, Kyratsis Y, Lawson W, Wickens H, Brannigan ET, Moore LS, et al. An analysis of the development and implementation of a smartphone application for the delivery of antimicrobial prescribing policy: Lessons learnt. J Antimicrob Chemother 2013 Apr;68(4):960-967 [FREE Full text] [doi: 10.1093/jac/dks492] [Medline: 23258314]

19. Moodley A, Mangino JE, Goff DA. Review of infectious diseases applications for iPhone/iPad and Android: From pocket to patient. Clin Infect Dis 2013 Oct;57(8):1145-1154 [FREE Full text] [doi: 10.1093/cid/cit455] [Medline: 23839999]

20. Schnall R, Iribarren SJ. Review and analysis of existing mobile phone applications for health care-associated infection prevention. Am J Infect Control 2015 Jun;43(6):572-576. [doi: 10.1016/j.ajic.2015.01.021] [Medline: 25748924]

21. Wellcome Trust (London, England), Good Business. Exploring the Consumer Perspective on Antimicrobial Resistance. 2015. URL: http://wellcomelibrary.org/item/b24978000\#?c=0\&m=0\&s=0\&cv=0 [accessed 2016-06-27] [WebCite Cache ID 6iaH0eNze]

22. McCullough AR, Parekh S, Rathbone J, Del Mar CB, Hoffmann TC. A systematic review of the public's knowledge and beliefs about antibiotic resistance. J Antimicrob Chemother 2016 Jan;71(1):27-33. [doi: 10.1093/jac/dkv310] [Medline: 26459555]

23. National Patient Safety Agency, National Research Ethics Service. Information Sheets \& Consent Forms: Guidance for Researchers \& Reviewers. London, UK: National Health Service (NHS); 2011 Mar. URL: http://www.wales.nhs.uk/sitesplus/ documents/866/Guidelines\%20NRES\%20on\%20Information\%20Sheet\%20\%26\%20Consent\%20Form.pdf [accessed 2016-06-27] [WebCite Cache ID 6iaIonQNV]

24. Attride-Stirling J. Thematic networks: An analytic tool for qualitative research. Qual Res 2001 Dec 01;1(3):385-405. [doi: 10.1177/146879410100100307]

25. Patient Safety Alert-Stage Two: Resources Addressing Antimicrobial Resistance Through Implementation of an Antimicrobial Stewardship Programme. London, UK: Public Health England, National Health Service; 2015 Aug. URL: http://www.england.nhs.uk/wp-content/uploads/2015/08/psa-amr-stewardship-prog.pdf [accessed 2016-06-27] [WebCite Cache ID 6iaJJi6Kh]

26. Antimicrobial Stewardship: Systems and Processes for Effective Antimicrobial Medicine Use. London, UK: National Institute for Health and Care Excellence; 2015 Aug. URL: https://www.nice.org.uk/guidance/ng15 [accessed 2016-06-20] [WebCite Cache ID 6iPFtp4Ne]

27. Von Holtz LA, Hypolite KA, Carr BG, Shofer FS, Winston FK, Hanson CW3, et al. Use of mobile apps: A patient-centered approach. Acad Emerg Med 2015 Jun;22(6):765-768 [FREE Full text] [doi: 10.1111/acem.12675] [Medline: 25998446]

28. Torous J, Friedman R, Keshavan M. Smartphone ownership and interest in mobile applications to monitor symptoms of mental health conditions. JMIR Mhealth Uhealth 2014;2(1):e2 [FREE Full text] [doi: 10.2196/mhealth.2994] [Medline: 25098314]

29. Mosa AS, Yoo I, Sheets L. A systematic review of healthcare applications for smartphones. BMC Med Inform Decis Mak 2012;12:67 [FREE Full text] [doi: 10.1186/1472-6947-12-67] [Medline: 22781312]

30. Chaffey D. Smart Insights. Mobile marketing statistics compilation URL: http://www.smartinsights.com/mobile-marketing/ mobile-marketing-analytics/mobile-marketing-statistics/ [accessed 2016-06-20] [WebCite Cache ID 6iPG6NFhj] 
31. Ofcom. CMR Facts \& Figures 2015. London, UK: Ofcom; 2015. URL: http://media.ofcom.org.uk/files/2015/ facts-figures-table15.pdf [accessed 2016-06-20] [WebCite Cache ID 6iPGEEoTH]

32. Hayakawa M, Uchimura Y, Omae K, Waki K, Fujita H, Ohe K. A smartphone-based medication self-management system with realtime medication monitoring. Appl Clin Inform 2013;4(1):37-52 [FREE Full text] [doi: 10.4338/ACI-2012-10-RA-0045] [Medline: 23650486]

33. Langebeek N, Nieuwkerk P. Electronic medication monitoring-informed counseling to improve adherence to combination anti-retroviral therapy and virologic treatment outcomes: A meta-analysis. Front Public Health 2015;3:139 [FREE Full text] [doi: 10.3389/fpubh.2015.00139] [Medline: 26042212]

34. IMS Institute for Healthcare Informatics. Patient Adoption of mHealth: Use, Evidence and Remaining Barriers to Mainstream Acceptance. Danbury, CT: IMS Health URL: http://www.imshealth.com/en/thought-leadership/ims-institute/reports/ patient-adoption-of-mhealth [accessed 2016-06-20] [WebCite Cache ID 6iPGMwOHm]

35. European Commission. 2016. eHealth projects - Research and innovation in the field of ICT for health and wellbeing: An overview URL: https://ec.europa.eu/digital-single-market/news/

ehealth-projects-research-and-innovation-field-ict-health-and-wellbeing-overview [accessed 2016-06-20] [WebCite Cache ID 6iPGJ9aI1]

\author{
Abbreviations \\ AMR: antimicrobial resistance \\ EAAD: European Antibiotic Awareness Day \\ ECCMID: European Congress for Clinical Microbiology and Infectious Diseases \\ GP: general practitioner \\ HCP: health care professional \\ HPRU: Health Protection Research Unit \\ NHS: National Health Service \\ NICE: National Institute for Health and Care Excellence \\ NIHR: National Institute for Health Research \\ PHE: Public Health England \\ RCT: randomized controlled trial
}

Edited by G Eysenbach; submitted 13.10.15; peer-reviewed by D Ashiru-Oredope, S Iribarren, J Eickholt; comments to author
14.02.16; revised version received 12.03.16; accepted 29.03.16; published 06.07.16
Please cite as:
Micallef C, McLeod M, Castro-Sánchez E, Gharbi M, Charani E, Moore LSP, Gilchrist M, Husson F, Costelloe C, Holmes AH
An Evidence-Based Antimicrobial Stewardship Smartphone App for Hospital Outpatients: Survey-based Needs Assessment Among
Patients
JMIR Mhealth Uhealth 2016;4(3):e83
URL: $\underline{\text { http://mhealth.jmir.org/2016/3/e83/ }}$
doi: $10.2196 /$ mhealth.5243
PMID: 27383743

(C) Christianne Micallef, Monsey McLeod, Enrique Castro-Sánchez, Myriam Gharbi, Esmita Charani, Luke SP Moore, Mark Gilchrist, Fran Husson, Ceire Costelloe, Alison H Holmes. Originally published in JMIR Mhealth and Uhealth (http://mhealth.jmir.org), 06.07.2016. This is an open-access article distributed under the terms of the Creative Commons Attribution License (http://creativecommons.org/licenses/by/2.0/), which permits unrestricted use, distribution, and reproduction in any medium, provided the original work, first published in JMIR mhealth and uhealth, is properly cited. The complete bibliographic information, a link to the original publication on http://mhealth.jmir.org/, as well as this copyright and license information must be included. 